\title{
Effects of exercise infomation using social network service(SNS) on physical activity and psychological variables among inactive college students
}

\author{
Dojin An, Youngho Kim, \& Soojin Kang* \\ Seoul National University of Science and Technology
}

\begin{abstract}
[Purpose] The current study investigated the effects of exercise information using social network service(SNS) to identify changes of physical activity and psychological variables among inactive college students. [Methods] Inactive college students(30 experimental group, 30 control group) were voluntarily participated in the 12-weeks intervention. During this period, the experimental group received exercise information through SNS. And all study participants' physical activity, stages of physical activity, self-efficacy, motivation, and perceived benefits and barriers were measured at the pre, mid and post intervention. Frequency analysis, chi-square test, 2-way ANOVA RM were conducted to analyze data obtained in the study. All procedures were performed by using SPSS 23.0. [Results] The exercise information intervention using SNS during 12 weeks had a positive effect on the stages of physical activity of inactive college students, and there were statistically significant differences. In addition, physical activity, perceived benefits and barriers, self-efficacy, motivation positively improved after the intervention, but there were no statistically significant differences between experimental and control group. [Conclusions] The present study suggests that psychological strategies using various SNS programs have positive effects for inactive college students to increase physical activity and its related psychological variables.
\end{abstract}

Key words: Inactive college students, Physical activity, Psychological strategy, Social network service, Transtheoretical model

논문 투고일 : 2020. 03. 16 .

논문 수정일 : 2020. 05. 07.

게재 확정일 : 2020. 05. 20.

* 교신저자 : 강수진(eostm2000@ naver.com).

* 이 논문은 2016년 대한민국 교육부와 한국연구재단의 지원을 받아 수행된 연구임(NRF-2016S1A5B5A02024293).

\begin{abstract}
서 론
우리나라의 대학 또는 전문대학 진학률은 $67.7 \%$ 로 (Statistics Korea: Korean indicator of education, 2019), 초기 성인기에 해당하는 20대의 대부분은 대학생 이라고 할 수 있다. 타율적으로 일과가 구성되었던 초, 중, 고교생 시기와는 다른 자율적인 대학생 시기는 음주, 흡연 등으로 대표되는 건강위험행동 습득이 쉬운 만큼, 올바른 건강습관 형성에 중요한 생애전환기이다. 또한, 이 시기는 다른 연령층에 비해 생활방식이 확고하게 형성
\end{abstract}


되어 있지 않고, 행동의 수정가능성이 크기 때문에 대학 생들은 신체적, 정서적, 사회적 변화를 겪으며 성인기의 건강습관을 형성해 나간다(Burbaker, 1983). 따라서, 해당시기 동안의 운동습관은 졸업 후 규칙적인 신체활동 참여의 강력한 예측인자 중 하나로 보고되고 있다 (Jackson \& Howton, 2008). 하지만, 대학생들은 극심 한 취업경쟁을 딿고 사회진출을 하기 위한 학문적, 사회 적 활동을 수행함(Seol, 1996)에 있어 규칙적인 신체활 동에 참여하기보다는 대부분의 시간을 좌업활동에 할애 하고 있다. 또한, 대학 신입생을 대상으로 한 연구 결과에 따르면 여가시간에는 신체 비활동 수치를 나타내는 TV 시청시간이나 컴퓨터 이용시간이 신체활동에 참여하는 시간보다 많은 것으로 나타나 대학생들의 신체활동 증진 의 필요성이 매우 높은 것으로 조사되었다(Park et al., 2001). Statistics Korea: Korean indicator of physical activity(2019)의 조사결과에 따르면, 20대의 신체활동 실천율은 $36.8 \%$ 로 매우 낮은 실정이다. 한국 과 미국의 대학생을 대상으로 신체활동을 비교한 연구 (Kim, 2004)에 따르면 한국의 대학생들은 $38.2 \%$ 가 규 칙적으로 신체활동을 하고 있는 것으로 나타났고, 미국의 대학생들은 $56.4 \%$ 로 보고되고 있다. 중강도 이상의 신 체활동에 참여하고 있는 국내 대학생의 비율은 $24.6 \%$ 로 나타났으며(Ministry of Health and Welfare, 2011), 중강도에서 고강도의 신체활동에 참여하는 국내 대학생 의 비율은 미국 대학생의 절반 수준에도 미치지 못하고 있다(Kim et al., 2011). 이에따라, 최근 대학생들의 건 강 증진은 중요한 사회적 문제로 부각되고 있기 때문에 전략적 접근이 필요한 시점이다. 대학생들의 신체활동 부 족은 심혈관계 질환 관련 사망률의 주된 위험요인으로 지 적되고 있으며 (Lengfelder, 2001), 당뇨, 정신질환과 같 은 만성적 생활 습관병의 주요 원인으로 보고되고 있다 (Brown et al., 2005; United States Department of Health and Human Services, 1996). 신체활동 참여율 을 높이기 위한 운동심리학의 연구분야에서는 동기, 자기 효능감, 심상, 도식, 의도, 태도, 방해요인, 그리고 재미 와 같은 심리적 특성이 신체활동의 증진과 지속에 영향을 받는다고 보고하고 있다(Banting et al., 2009; Cumming, 2008; Kim, 2006). 이러한 선행연구들을 토 대로, 대학생들의 신체활동 참여를 증진시키기 위한 캠페
인과 신체활동에 관한 정보 제공, 사회생태적 접근과 같 은 환경과 정책을 아우르는 대학생에게 적합한 운동정보 와 다양한 신체활동 프로그램의 개발이 필요할 것으로 사 료된다(Kim et al., 2011).

이와같은 다양한 심리적 특성과 관련된 이론적 모형들 중 Prochaska \& Marcus(1994)에 의해 운동영역 분야 에 소개된 단계변화모형(Transtheoretical model)은 건 강행동을 단계적, 유기적으로 변화하는 과정으로 설명하 고 있기 때문에 운동행동의 변화적 특성을 규명하는데 매 우 유용한 이론이다(Kim, 2002; Marcus et al., 1996). 이에, 신체활동 프로그램을 어떤 개인에게 적용했을 때 항상 효과적일 수는 없었던 원인과 문제를 이해할 수 있 으며(Ashworth, 1997), 효과적인 신체활동 처치전략을 개발하는데 중요한 이론적 틀을 제공하고 있다(Sallis \& Owen, 1999). Lee(2004)의 연구에서는 단계변화모형을 대학생들의 운동행동에 적용하여 대학생들의 운동행동 변 화단계를 예측하였고, 운동행동의 각 단계에 영향을 미치 는 심리변인을 규명하였다. 연구결과에 따르면 단계변화 모형의 모든 하위변인(자기효능감, 의사결정균형, 변화과 정)은 운동행동단계와 유의한 관련이 있는 것으로 나타났 고, 운동방해요인을 제외한 모든 하위변인들이 운동행동 단계와 유의한 상관이 있는 것으로 나타났다. 이러한 단계 변화모형을 토대로 한 단계일치전략(Stage-matched intervention)은 건강운동심리학 영역에서 신체활동과 관련된 개인의 다양한 심리적 욕구들을 처치하는데 효과 적인 전략이라고 할 수 있다(Blissmer \& McAuley, 2002; Kim et al., 2004). 실제로 성인들을 대상으로 단 계일치 처치전략을 적용한 $\mathrm{Kim}(2007)$ 의 연구에서 처치 를 받은 성인들의 신체활동 단계와 자기효능감, 의사결정 균형, 변화과정, 운동수준 등의 심리 변인들이 긍정적으 로 변화된 것을 확인하였다. 또한 Kim et al. (2013)의 연 구에서 단계변화모형을 토대로 만들어진 심리수정 프로 그램을 적용한 비만관리 프로그램이 남자비만청소년들 의 체중감소와 신체활동 수준 및 심리 변인을 변화시키는 데 있어서 긍정적인 효과가 있는 것을 확인하였다.

최근 인터넷 매체와 정보통신기술의 혁신적인 발달로 인해 온라인상의 소통관계는 빠르게 변화하고 있다. 노트 북과 스마트폰 등 휴대가 편리한 기기가 빠른 속도로 발 달하였고, 언제 어디서나 무선 인터넷 사용이 자유로워졌 
기 때문에 다양한 정보를 손쉽게 주고 받을 수 있는 시대 가 되었다. 이로 인해 무선데이터 이용량이 급속도로 증 가하면서 웹사이트 기반이 아닌 모바일 형태의 무선 인터 넷 서비스들이 증가하고 있는 실정이다(Cho, 2013). 특 히, 사회적 관계를 인터넷 공간으로 가져와 개인이 인터 넷의 중심이자 하나의 연결지점이 되는 Social Network Service(SNS)가 모바일 기술과 결합되어 새로운 커뮤니 케이션 도구로 사용되고 있다(Lee \& Jung, 2010). SNS는 사람들 간의 커뮤니케이션을 원활히 하기 위해 페 이스북, 인스타그램 또는 카카오톡과 같은 온라인상의 활 동을 지속적으로 강화시키는 도구로써 중요한 역할을 하 고 있다. 즉, SNS는 다양한 사람들에게 필요한 여러 가지 정보를 쉽고 빠르게 얻을 수 있게 할 뿐만 아니라 인맥관 계도 맺을 수 있도록 지원하고 있다. SNS를 통한 의사소 통은 인간의 생활을 편리하게 하며, 인간관계의 급속한 변화를 이끌고 있다(Keum, 2016).

2019년 인터넷 이용 실태조사에 따르면, SNS 이용률 은 20대(87.1\%), 30대(77.2\%), 만6-19세(54.5\%) 순 으로 나타났다. 만 6세 이상 $\mathrm{SNS}$ 이용자 $(63.8 \%)$ 의 대부 분이 페이스북(66.3\%), 인스타그램 $(49.9 \%)$, 카카오스 토리 $(38.1 \%)$ 등 프로필 기반의 서비스를 이용하고 있는 것으로 조사되었다(Ministry of Science and ICT, 2019).

최근 해외의 예방의학 및 건강운동심리학의 분야에서 는 SNS를 활용한 신체활동 증진전략이 신체활동 참여율 을 높이는데 긍정적으로 작용하였다고 보고하였고 (David et al., 2012; Jingwen et al., 2016), 또 다른 연구에서는 인스타그램과 같은 소셜미디어에 게시되어 있는 'fitspiration images or text'가 개인의 신체활동과 관련된 심리 변인에 미치는 영향을 규명하였다(Deighton-Smith $\&$ Bell, 2018). 또한, 다양한 연령층의 건강과 신체활동 을 촉진하기 위해 스마트폰앱 사용의 장, 단점을 조사한 연구(Hongu et al., 2014), 휠체어 사용자들의 신체활동 참여 증진을 위해 스마트폰앱을 활용한 상담 프로그램을 개발한 연구(Best, et al., 2016)와 알콜중독 환자를 위 한 신체활동 애플리케이션 개발 연구(Abrantes et al., 2019) 등 다양한 대상과 분야에서 소셜미디어를 신체활 동 프로그램에 적용한 연구가 꾸준히 진행되고 있는 실정 이다. 국내의 사례를 살펴보면, 스마트폰앱을 기반으로
한 걷기 및 운동 프로그램을 개발하여 효과를 검증한 연 구(Choi \& Chae, 2020; Ki \& So, 2020)가 수행되었을 뿐만아니라, 실제로 이러한 프로그램들이 현장에서 효율 적으로 적용될 수 있도록 활발한 연구가 진행되고 있다. 하지만, 국내 건강운동심리학의 영역에서 SNS를 활용하 여 신체활동 참여에 영향을 미치는 주요 심리 변인들을 다룬 연구는 전무한 실정이다.

현재까지 단계변화모형을 바탕으로 한 단계일치전략 과 심리수정 프로그램을 적용한 여러 연구들이 개인의 신 체활동과 이와 관련된 심리 변인들을 긍정적으로 향상시 키는데 있어 유의하게 작용한다는 결과를 보고하고 있지 만(Griffin-Blake \& DeJoy, 2006; Lippke et al., 2005; Kim, 2007; Kim et al., 2013), 대부분의 연구가 현장에서 직접적으로 처치전략을 적용함에 따르는 시간 부족, 공간의 제약 등으로 인해 신체활동을 지속적으로 실시하는데 한계가 있다는 단점이 있다. 반면, SNS는 다 른 매체에 비해 상대적으로 비용이 거의 들지 않고, 시간 과 공간의 제약에 비교적 자유롭기 때문에 SNS 사용빈도 가 잦은 대학생들에게 신체활동의 필요성과 중요성, 그리 고 운동의 이득에 관한 정보와 생활속에서 실천할 수 있 는 유익한 운동습관 형성에 도움이 되는 정보를 SNS를 통해 제공한다면 신체활동 실천 의도를 가지고 있지 않은 대학생들에게 신체활동에 대한 동기를 심어주는데 더욱 효과적일 것이다. 따라서, 본 연구에서는 단계일치전략 을 기반으로 한 운동정보를 SNS를 통해 제공함으로써 대 학생의 신체활동량, 신체활동 수준, 의사결정균형, 자기 효능감, 동기와 같은 심리변인에 긍정적인 변화가 있는지 를 확인하여 $\mathrm{SNS}$ 를 통한 운동정보제공의 유효성을 검증 하는데 그 목적이 있다.

\section{연구방법}

\section{연구대상}

본 연구에서는 단계변화모형을 구성하고 있는 개념 중 변화 단계의 계획전 단계, 계획 단계, 준비 단계에 해당하 는 신체활동 참여 의도가 없고, 현재 신체활동을 하지 않 고 있는 대학생을 '비활동 대학생'으로 정의하였다. 표본 
추출은 서울에 위치한 대학교에 재학중인 학생을 대상으 로 하였고, 비확률표본추출법을 이용하여 연구에 참여하 고자 하는 대상자에게 250 부의 설문지를 배부하였다. 배 부한 설문지를 회수한 뒤, 연구 목적에 맞는 대상자 선정 을 위해 참여 희망자가 설문에 답한 내용을 바탕으로 '비 활동 대학생'에 해당하는 대학생을 목적표집하여 실험집 단 30명 통제집단 30명을 선정하였다. 실험집단의 평균 연령은 $22.93( \pm 1.89)$ 세이며, 통제집단의 평균연령은 $22.7( \pm 1.74)$ 세로 집단별 연령은 비슷한 수준이다.

또한, 연구자가 측정 전 연구의 목적과 방법 등을 설명 한 후 참여자들로부터 연구참여 동의서를 받았다. 취득한 개인정보를 연구목적 외에 사용하지 않을 것, 연구에 자 유롭게 참여하고 철회할 수 있다는 점을 동의서에 표기하 여 서명하도록 한 후 연구를 진행하였다.

\section{측정 항목 및 방법}

\section{인구통계학적 변인}

연구 참여자의 인구통계학적인 특성을 파악하기 위하 여 본 연구에서는 연령과 과거 운동경험을 질문하였으며, 자기기입법으로 측정하였다.

\section{신체활동 단계 질문지}

연구 참여자들의 신체활동 단계를 알아보기 위하여 Stage of Change Scale for Exercise(Marcus et al., 1992)를 $\operatorname{Kim}(2002)$ 이 번안하여 사용한 한국판 운동행 동변화단계 질문지를 사용하였다.

이 질문지는 각 개인의 운동행동의 단계를 설명하는 5 단계로 정의한 내용으로 구성되어 있으며, 연구 참여자는 다섯 단계 중 규칙적인 운동에 참여하고자 하는 자신의 의도와 실제 운동행동과 일치하다고 생각하는 하나의 단 계를 선택하도록 하였다. $\operatorname{Kim}(2002)$ 에 따르면, 운동행 동단계 질문지의 신뢰도는 .85로 나타났고, 신체활동 회 상 질문지와의 내적타당도는 .81로 보고되었다.

\section{신체활동량 질문지}

연구 참여자들의 운동 강도는 신체활동량을 Godin \& Shephard(1985)의 Leisure Time Physical Activity Questionnaire를 Kim et al.(2006)이 한국어로 번역하
여 표준화한 한국판 여가시간 신체활동 질문지를 사용하 여 측정하였다. 이 연구에서 종속변인으로 설정한 운동 강 도에 관한 질문은 연구 참여자들이 일주일에 평균 어느 정 도 수준의 운동을 하는지를 알아보고 있다. 강한 강도, 중 간 강도, 약한 강도의 수준으로 나누어 연구 참여자들에게 동일한 기준으로 운동 강도의 정의를 숙지하도록 하고, 최 소 15 분 이상 운동을 한 횟수를 직접 기입하였다. 응답한 운동수준 점수는 총 $\mathrm{MET}$ (metabolic equivalent)값을 구 하기 위하여 각 운동강도별로 곱해져서 합산된다(강한 강도의 운동횟수 $\times 9)+($ 중간 강도의 운동횟수 $\times 5)+($ 약한 강도의 운동횟수 $\times 3)$. 질문지의 구성타당도는 가속도계 와의 상관관계로 검증하였고(Spearman's rho= .77), 신뢰도는 Cronbach's $\alpha=.82$ 로 보고되었다(Kim et al., 2006).

\section{의사결정균형 질문지}

신체활동에 대한 이득과 장애 요인을 어떻게 지각하는 지를 알아보기 위하여 Plotnikoff et al. (2001)이 개발한 Decision Balance Scale for Exercise를 Kim et al.(2006)이 번안하여 표준화한 한국판 의사결정균형 질 문지를 사용하였다. 질문지는 신체활동에 대한 개인의 태 도를 측정하는 것으로 2 개의 하위변인 10 문항으로 구성 되어 있다(신체활동의 이득 요인 5 문항, 신체활동의 장 애 요인 5 문항). 연구 참여자들은 각 문항에 기술된 내용 에 대한 자신의 지각정도를 “전혀 그렇지 않다(1)" 에서부 터 “아주 그렇다(5)" 까지 5단계의 Likert 척도로 반응하 였다. test-retest 방법이 질문지의 안정성을 측정하기 위하여 수행되었으며, 신뢰도는 신체활동 이득 요인 $r=.91$ 그리고 신체활동 장애 요인 $r=.89$ 로 보고되었다.

\section{운동자기효능감 질문지}

운동자기효능감 측정을 위해 Bandura(1997)에 의해 서 개발된 Exercise Self-efficacy Scale을 Kim(2004)이 번안하여 신뢰도와 타당도를 검증한 한국판 운동자기효 능감 질문지를 사용하였다. 질문지에서 연구 참여자들은 여러 가지 상황에서 운동수행에 영향을 미치는 개인적 능 력의 지각 및 환경적 조건과 관련된 각 문항에 대해 자기 자신이 확신하는 정도에 응답한다. 운동자기효능감 질문 지의 반응범위는 각 문항이 제시하는 상황에서 연구 참여 
자들이 운동을 할 수 있는 개인의 확신 정도를 점수로 나 타내며, "전혀 자신이 없다(1)" 에서부터 “정말 자신이 있 다(5)" 까지 5단계의 Likert 척도로 구성되어 있다. 사전 조사를 통한 한국판 운동자기효능감 질문지의 신뢰도는 Cronbach's $\alpha$ 값이 .94, test-retest $r$ 값이 .89로 보고되었다.

\section{운동 동기 질문지}

자기결정성이론을 토대로 한 운동 행동의 내적, 외적 동기 요인을 알아보기 위하여 Wilson et al. (2004)이 수 정 보완한 Behavioral Regulation on Exercise Questionnaire(Mullan et al., 1997)를 Kim et al.(2007)이 한국어로 번안한 운동행동규제 질문지-2를 사용하였다. 운동행동규제 질문지는 무동기 4 문항, 외적 규제 4문항, 의무감 규제 3 문항, 확인규제 4 문항, 내적규 제 3 문항으로 총 18 개의 문항으로 이루어져 있으며, "전 혀 그렇지 않다(1)"에서부터 “매우 그렇다(5)" 까지 5단 계의 Likert 척도로 구성되어 있다. 질문지의 구성타당도 는 요인분석을 통해 검증되었으며, 하위변인들의 Cronbach's $\alpha$ 계수는 .84-.91로 보고되었다.

\section{연구절차}

본 연구는 비활동 대학생 총 60 명을 목적표집하여 운 동정보를 제공받기 전에 일반적 특성(연령, 과거 운동경 험 등)과 심리 변인(변화 단계, 운동 이득 및 장애 요인, 운동자기효능감, 운동동기), 신체활동량을 측정하였다. 그리고 연구 참여자들을 실험집단(30명)과 통제집단(30 명)으로 구분하였고, 실험집단에게는 동의를 구한 후 카 카오톡 아이디를 조사하여 단체 채팅방을 개설했다. 진행 될 실험에 관한 충분한 설명 후 매주 수요일 단체 채팅방 에 연구자의 네이버포스트에 게시된 운동정보를 '링크'를 통하여 2018년 4월 4일 수요일부터 2018년 6월 20일 수 요일까지 12 주 동안 1 주일에 1 회, 총 12 회에 걸쳐 제공 하였고, 통제집단에게는 어떠한 메시지도 제공하지 않았 다. 프로그램 실시 6주, 12 주 후, 연구 참여자들은 프로 그램을 적용하기 전과 동일하게 일반적 특성, 심리 변인, 신체활동량을 측정하였다. 연구 참여자들의 참여율을 유 지하고 참여의지를 높이기 위해서 SNS를 이용하여(카카 오톡 단체 채팅방 이용) 주 1 회 (매주 월요일), 참여 학생 들에게 다음 주 프로그램의 목표와 내용 등을 소개하는 $\mathrm{SNS}$ 메세지를 발송하였다. 연구 참여자들의 실험 참여

Table 1 . The topics and contents about physical activity information

\begin{tabular}{|c|c|c|c|c|}
\hline \multicolumn{5}{|c|}{ Physical activity information } \\
\hline Stages & Weeks & Subjects & Key contents & Psychological strategies \\
\hline \multirow{5}{*}{$\begin{array}{l}\text { Pre } \\
\text { contemplation }\end{array}$} & Week 1 & \multirow{5}{*}{$\begin{array}{l}\text { Conscious } \\
\text { raising }\end{array}$} & $\begin{array}{l}\text { Introduction to physical activity information in the } \\
\text { precontemplation stage }\end{array}$ & \multirow{5}{*}{$\begin{array}{l}\text { (1) Getting knowledge and } \\
\text { information } \\
\text { (2) A positive approach to } \\
\text { physical activity }\end{array}$} \\
\hline & Week 2 & & $\begin{array}{l}\text { Extending disability adjusted life expectancy, } \\
\text { physical and mental disease mitigation }\end{array}$ & \\
\hline & Week 3 & & Information about walking & \\
\hline & Week 4 & & Improving the qualilty of life & \\
\hline & Week 5 & & Reinforcement of cognitive function & \\
\hline \multirow{3}{*}{ Contemplation } & Week 6 & \multirow{3}{*}{$\begin{array}{c}\text { Getting } \\
\text { - information } \\
\text { about physical } \\
\text { activity }\end{array}$} & $\begin{array}{l}\text { Introduction to physical activity information in the contemplation } \\
\text { stage }\end{array}$ & \multirow{3}{*}{$\begin{array}{l}\text { (1) Intensity of daily activity } \\
\text { - (2) Kind of daily activity }\end{array}$} \\
\hline & Week 7 & & Attempts to overcome personal and environmental obstructions & \\
\hline & Week 8 & & Specific information about physical activity & \\
\hline \multirow{4}{*}{ Preparation } & Week 9 & \multirow{4}{*}{$\begin{array}{l}\text { Self and } \\
\text { environmental } \\
\text { - reevaluation }\end{array}$} & $\begin{array}{l}\text { Introduction to physical activity information in the preparation } \\
\text { stage }\end{array}$ & \multirow{4}{*}{$\begin{array}{l}\text { (1) Encouraging } \\
\text { environmental changes } \\
\text { (2) Making time for exercise } \\
\text { in everyday life } \\
\text { - (3) Planning and progress } \\
\text { review }\end{array}$} \\
\hline & Week 10 & & Short-term goal setting & \\
\hline & Week 11 & & Using relationships & \\
\hline & Week 12 & & Formulating clear objectives & \\
\hline
\end{tabular}


Table 2. Differences in change of physical activity stages between experimental and control group

\begin{tabular}{|c|c|c|c|c|c|c|c|c|c|}
\hline & \multirow{2}{*}{ Group } & \multicolumn{5}{|c|}{ Stages of physical activity } & \multirow{2}{*}{ Total (\%) } & \multirow{2}{*}{$\kappa^{2}$} & \multirow{2}{*}{$p$} \\
\hline & & $\mathrm{PC}$ & $\mathrm{CO}$ & PR & $\mathrm{AC}$ & MA & & & \\
\hline \multirow{2}{*}{${ }^{1}$ Baseline - } & experimental & $3(10.00)$ & $7(23.30)$ & $20(66.70)$ & $0(0.00)$ & $0(0.00)$ & $30(100)$ & \multirow{2}{*}{4.316} & \multirow{2}{*}{.116} \\
\hline & control & $6(20.00)$ & $12(40.00)$ & $12(40.00)$ & $0(0.00)$ & $0(0.00)$ & $30(100)$ & & \\
\hline & total & $9(15.00)$ & $19(31.70)$ & $32(53.30)$ & $0(0.00)$ & $0(0.00)$ & $60(100)$ & & \\
\hline \multirow{2}{*}{${ }^{2}$ Week 6} & experimental & $2(6.70)$ & $7(23.30)$ & $14(46.70)$ & $6(20.00)$ & $1(3.30)$ & $30(100)$ & \multirow{2}{*}{1.368} & \multirow{2}{*}{.850} \\
\hline & control & $4(13.30)$ & $9(30.00)$ & $11(36.70)$ & $5(16.70)$ & $1(3.30)$ & $30(100)$ & & \\
\hline & total & $6(10.00)$ & $16(26.70)$ & $25(41.70)$ & 11(18.30) & $2(3.30)$ & $60(100)$ & & \\
\hline \multirow{2}{*}{${ }^{3}$ Week 12} & experimental & $0(0.00)$ & $5(16.70)$ & $7(23.30)$ & $13(43.30)$ & $5(16.70)$ & $30(100)$ & \multirow{2}{*}{14.237} & \multirow{2}{*}{.007} \\
\hline & control & $3(10.00)$ & $13(43.30)$ & $9(30.00)$ & $4(13.30)$ & $1(3.30)$ & $30(100)$ & & \\
\hline & total & $3(5.00)$ & $18(30.00)$ & $16(26.70)$ & $17(28.30)$ & $6(10.00)$ & $60(100)$ & & \\
\hline
\end{tabular}

PC:Precontemplation CO:Contemplation PR:Preparation AC:Action MA:Maintenance

를 확인하기 위해 게시물을 읽고 난 후 댓글을 작성하도 록 공지하였다. 제공된 신체활동 관련 운동정보의 주제 및 내용은 〈table 1〉과 같다.

\section{통계 처리}

본 연구의 통계분석을 위해, IBM SPSS 23.0을 활용 하였으며, 다음과 같은 통계분석 방법을 실시하였다. 첫 째, 본 설문에 참여한 응답자의 특성을 파악하기 위해 평 균, 표준편차, 첨도, 왜도를 산출하였다. 둘째, 연구 참여 자의 신체활동 단계를 파악하기 위해 빈도분석을 실시하 였다. 셋째, 운동정보제공에 따른 실험, 통제집단별 신체 활동단계 분포 비율의 차이를 검증하기 위해 카이제곱검 정 (Chi-square test)을 실시하였다. 넷째, 운동정보제공 에 따른 실험, 통제집단별 신체활동량과 주요 심리 변인 의 변화 차이를 검증하기 위해 반복측정 분산분석 (Two-way ANOVA with repeated-measures on all factors)을 실시하였다. 수집된 자료의 통계적인 유의수 준을 검정하기 위하여 유의수준을 $p<.05$ 로 설정하였다.

\section{연구결과}

\section{신체활동 단계의 변화}

$\mathrm{SNS}$ 를 활용한 운동정보제공 유무에 따른 실험, 통제
집단의 신체활동단계 변화의 차이를 비교하기 위해 교차 분석을 실시한 결과는 〈table 2 〉와 같다. 사전 검사와 6 주차의 검사 결과에서는 두 집단 모두 신체활동 단계가 계획 전 준비 단계에 분포하고 있었으며 집단 간의 유 의한 차이가 없었지만, 12 주 후 검사 결과에서는 실험집 단의 신체활동 단계는 행동 단계와 유지 단계까지 변화를 보였다. 반면, 통제집단은 큰 변화를 보이지 않았다. 집단 별 신체활동단계 변화의 차이 결과에서는 실험, 통제집단 간 유의한 차이를 보였다.

\section{단계변화모형 하위요인 및 신체활동량의 변화}

〈table 3〉은 SNS를 이용한 운동정보제공이 비활동 대 학생의 신체활동량 및 관련 심리 요인에 미치는 영향을 알아보기 위해 수행한 반복측정 분산분석의 결과이다. 시 간의 흐름에 따라 제공되는 운동정보의 양이 늘어나면서 실험집단의 신체활동량은 늘어났으며, 통계적으로 유의 한 차이를 보였고 $(F=5.340, p=.006)$, 시간과 집단 간 의 상호작용 효과를 분석한 결과에서는 실험집단이 통제 집단보다 더 높은 신체활동량을 보였지만, 집단 간의 유 의한 차이는 나타나지 않았다.

실험집단의 운동의 장점에 관한 인식도 시간의 흐름에 따라 높아졌고, 운동의 단점에 관한 인식은 감소하였으 며, 통계적으로 유의한 차이를 보였다(운동장점 $F=11.891, p=.001$; 운동단점 $F=4.257, p=.016$ ). 하지만, 시간과 집단 간의 상호작용 효과를 분석한 결과 
Table 3. Two-way ANOVA RM of the study variables by group

\begin{tabular}{|c|c|c|c|c|c|c|c|c|}
\hline $\begin{array}{l}\text { Psychological } \\
\text { variables }\end{array}$ & Group & $\mathrm{N}$ & $\begin{array}{l}{ }^{1} \text { Baseline } \\
(\mathrm{M} \pm \mathrm{SD})\end{array}$ & $\begin{array}{l}{ }^{2} \text { Week } 6 \\
(\mathrm{M} \pm \mathrm{SD})\end{array}$ & $\begin{array}{c}{ }^{3} \text { Week } 12 \\
(\mathrm{M} \pm \mathrm{SD})\end{array}$ & $\begin{array}{c}F \\
\text { time }\end{array}$ & $\begin{array}{c}F \\
\text { time } \times \text { group }\end{array}$ & **Post hoc \\
\hline \multirow{2}{*}{$\begin{array}{l}\text { Physical } \\
\text { activity }\end{array}$} & experimental & 30 & $24.70 \pm 18.75$ & $32.53 \pm 21.85$ & $36.40 \pm 19.38$ & \multirow{2}{*}{$5.340^{*}$} & \multirow{2}{*}{.408} & \multirow{2}{*}{$1<2,3$} \\
\hline & control & 30 & $25.27 \pm 18.90$ & $30.67 \pm 16.47$ & $31.77 \pm 22.42$ & & & \\
\hline \multirow{2}{*}{$\begin{array}{c}\text { Perceived } \\
\text { benefits }\end{array}$} & experimental & 30 & $3.95 \pm 0.52$ & $4.11 \pm 0.50$ & $4.13 \pm 0.60$ & \multirow{2}{*}{$11.891^{*}$} & \multirow{2}{*}{1.842} & \multirow{2}{*}{$1<2,3$} \\
\hline & control & 30 & $3.95 \pm 0.63$ & $4.17 \pm 0.60$ & $4.35 \pm 0.54$ & & & \\
\hline \multirow{2}{*}{$\begin{array}{c}\text { Perceived } \\
\text { barriers }\end{array}$} & experimental & 30 & $2.49 \pm 0.54$ & $2.35 \pm 0.61$ & $2.30 \pm 0.55$ & \multirow{2}{*}{$4.257^{*}$} & \multirow{2}{*}{.094} & \multirow{2}{*}{$1,2>3$} \\
\hline & control & 30 & $2.79 \pm 0.72$ & $2.68 \pm 0.70$ & $2.57 \pm 0.63$ & & & \\
\hline \multirow{2}{*}{$\begin{array}{c}\text { Exercise } \\
\text { self-efficacy }\end{array}$} & experimental & 30 & $2.93 \pm 0.65$ & $3.03 \pm 0.68$ & $3.24 \pm 0.59$ & \multirow{2}{*}{$10.369^{*}$} & \multirow{2}{*}{.754} & \multirow{2}{*}{$1,2<3$} \\
\hline & control & 30 & $2.80 \pm 0.60$ & $2.99 \pm 0.58$ & $3.05 \pm 0.59$ & & & \\
\hline \multirow{2}{*}{ Amotivation } & experimental & 30 & $1.56 \pm 0.56$ & $1.55 \pm 0.61$ & $1.40 \pm 0.52$ & \multirow{2}{*}{1.643} & \multirow{2}{*}{.131} & \\
\hline & control & 30 & $1.58 \pm 0.47$ & $1.58 \pm 0.55$ & $1.49 \pm 0.45$ & & & \\
\hline \multirow{2}{*}{$\begin{array}{l}\text { External } \\
\text { regulation }\end{array}$} & experimental & 30 & $1.90 \pm 0.69$ & $2.07 \pm 0.79$ & $1.95 \pm 0.71$ & \multirow{2}{*}{.593} & \multirow{2}{*}{.537} & \\
\hline & control & 30 & $1.80 \pm 0.64$ & $1.80 \pm 0.59$ & $1.78 \pm 0.72$ & & & \\
\hline \multirow{2}{*}{$\begin{array}{l}\text { Introjected } \\
\text { regulation }\end{array}$} & experimental & 30 & $1.74 \pm 0.71$ & $1.81 \pm 0.82$ & $1.77 \pm 0.84$ & \multirow{2}{*}{.991} & \multirow{2}{*}{.345} & \\
\hline & control & 30 & $1.52 \pm 0.52$ & $1.70 \pm .0 .73$ & $1.69 \pm 0.59$ & & & \\
\hline \multirow{2}{*}{$\begin{array}{l}\text { Identified } \\
\text { regulation }\end{array}$} & experimental & 30 & $3.48 \pm 057$ & $3.66 \pm 0.53$ & $3.79 \pm 0.63$ & \multirow{2}{*}{$8.286^{*}$} & \multirow{2}{*}{.572} & \multirow{2}{*}{$1,2<3$} \\
\hline & control & 30 & $3.53 \pm 0.72$ & $3.57 \pm 0.62$ & $3.78 \pm .0 .60$ & & & \\
\hline \multirow{2}{*}{$\begin{array}{l}\text { Intrinsic } \\
\text { regulation }\end{array}$} & experimental & 30 & $3.90 \pm 0.76$ & $3.81 \pm 0.75$ & $3.91 \pm 0.74$ & \multirow{2}{*}{.955} & \multirow{2}{*}{.770} & \\
\hline & control & 30 & $3.69 \pm 0.93$ & $3.79 \pm 0.89$ & $3.90 \pm 0.85$ & & & \\
\hline
\end{tabular}

$* p<.05, * *$ Bonferroni's comparing means of differences $(p<.05)$

에서는 실험집단과 통제집단을 비교하였을 때 통계적으 로 유의한 차이가 나타나지 않았다. 또한, 시간의 흐름에 따라 실험집단의 운동자기효능감은 높아졌으며, 통계적 으로 유의한 차이를 보였다 $(F=10.369, p=.001)$. 또 한, 시간과 집단 간의 상호작용 효과를 분석한 결과에서 는 실험집단이 통제집단보다 더 높은 운동자기효능감을 보였지만, 집단 간의 유의한 차이는 나타나지 않았다.

동기의 측정 항목 중 시간의 흐름에 따른 변화에서는 확인규제의 항목이 유의한 변화를 보였고 $(F=8.286$, $p=.001)$, 그 외의 무동기, 외적규제, 의무감규제, 내적 규제의 항목에서는 통계적으로 유의한 차이가 없었다. 또 한, 시간과 집단 간의 상호작용 효과를 분석한 결과에서 도 실험집단과 통제집단을 비교하였을 때 동기의 모든 항 목에서 통계적으로 유의한 차이가 나타나지 않았다.

\section{논 의}

본 연구는 신체활동 참여 의도가 없고, 현재 신체활동에 참여하지 않고 있는 비활동 대학생을 대상으로 하였다. 12 주 동안의 SNS를 활용한 운동정보제공이 비활동 대학 생의 신체활동과 심리 변인에 미치는 영향을 규명하기 위 해 신체활동 참여 증진을 위해 진행되었던 선행연구들과 본 연구의 결과를 토대로 비교, 분석하여 논의하였다.

본 연구에서 중재전략 이후 비활동 대학생의 신체활동 변화단계의 긍정적인 향상은 성인들에게 단계일치 처치전 략을 적용하여 신체활동 및 관련 심리변인들의 변화를 알 아본 $\operatorname{Kim}(2007)$ 의 연구결과와 일치한다. 특히, SNS를 활용한 운동정보제공이 비활동 대학생의 신체활동 변화단 계 향상에 유의하게 작용한 본 연구의 결과는 e-mail을 사 용한 자기교수적 처치전략을 적용하여 성인들의 신체활동 단계를 증가시키는데 유의하게 기여한 $\operatorname{Kim}(2007)$ 의 연 
구결과를 지지한다. $\operatorname{Kim}(2018)$ 의 연구에서는 타바타운 동과 심리수정기법의 적용이 여자중학생의 신체활동량 과 신체활동 변화단계 및 심리 변인이 통계적으로 유의한 차이를 보이며 증가했다고 밝히고 있다. 이러한 결과는 본 연구에서 단계변화모형을 기반으로 한 처치전략이 대 학생들이 가지고 있는 신체활동에 관한 심리변인의 긍정 적 변화에 미치는 영향을 검증하는 것과 맥락을 같이하고 있다. 또한, 운동프로그램을 적용한 뒤 스마트폰 애플리 케이션을 이용해 자신의 운동을 기록하게 하여 대학생의 신체활동 변화단계를 확인한 Kim의 연구(2012)와 유사 한 결과를 나타내고 있다.

Marcus \& Lewis (2003)는 신체활동 변화단계의 초기 단계에 해당하는 사람들에게는 신체활동 참여에 따르는 장점을 생각하게 하고, 관련 정보에 자주 노출될 수 있도 록 하는 '인지적 과정 (Cognitive processes)' 에 해당하는 처치전략을 적용하는 것이 효과적이라고 보고하였고, 많 은 연구들이 이를 검증하였다(Marcus \& Forsyth, 2003; Cardinal \& Kosma, 2004; Fallon et al., 2005; Griffin-Blake \& DeJoy, 2006; Lippke et al., 2005). 따라서, 본 연구에서는 이와같은 심리전략을 바탕으로 신 체활동 초보자의 인지를 재구성할 수 있도록 돕는 정보와 일상생활에서 신체활동을 쉽게 생활화 할 수 있는 실용적 이고 다양한 방법을 재미있게 구성하여 네이버포스트에 게시하였고, 카카오톡 그룹채팅방을 이용하여 연구 참여 자들에게 제공하였다. 제공된 정보는 휴대전화에서 한번 의 터치만으로 간편하게 확인할 수 있고, 자유롭게 댓글 을 작성할 수 있기 때문에 연구자-참여자 사이의 즉각적 인 의견교환과 피드백이 가능했다. 이는 연구 참여자들의 참여도와 흥미를 높일 수 있었고, 결과적으로 비활동 대 학생의 신체활동 단계의 심리적인 변화를 유도할 수 있었 다고 생각된다. 결론적으로, $\mathrm{SNS}$ 를 활용한 운동정보제 공은 SNS 이용률이 높은 대학생들의 신체활동 변화단계 를 향상시키는데 효율적이라고 사료된다.

신체활동과 단계변화모형을 바탕으로 한 운동정보제 공은 신체활동량과 이와 관련된 심리변인에 영향을 주는 것으로 나타났다. 대학생의 신체활동 참여요인에 따른 신 체활동량 차이를 분석한 선행연구에서 Park(2017)은 운 동지식에 대한 관심이 많고, 학창시절 체육수업 외 운동 프로그램 참여한 경험이 많은 대학생일수록 신체활동량
이 증가한다고 보고하였다. 본 연구에서는 연구자가 제공 한 운동정보에 노출될수록 실험집단의 신체활동량이 증 가하였으며, 이는 선행연구의 결과와 부분적으로 일치한 다. 또한, 실험집단과 통제집단 간의 비교에서도 차이가 나타났지만, 통계적으로 유의한 차이를 보이지 않은 결과 는 선행연구의 결과와 차이를 보였다.

본 연구의 주요 심리변인 중 자기효능감과 운동의 장 점에 대한 지각은 통계적으로 유의하게 증가한 반면에, 운동의 단점에 대한 지각요인은 유의하게 감소하였다. 즉, 운동이 주는 장점의 가치를 긍정적으로 인식하게 된 것으로 해석할 수 있다. 이와 관련된 선행연구에서는 심 리수정전략을 적용한 12 주 동안의 비만관리 프로그램이 비만청소년들의 체질량을 감소시키고, 신체활동에 대한 개인의 심리적 성향을 긍정적으로 변화시키는데 효과가 있다고 보고하였다(Kim et al., 2013). 이러한 결과는 본 연구에서 비활동 대학생들의 자기효능감과 운동의 장 점에 대한 지각이 증가하였던 점과 유사하고, 지각된 운 동의 단점요인이 감소한 점과 유사하다. 또한, 신체활동 량이 증가할수록 자기효능감, 자아존중감 등의 심리 변인 에 긍정적 영향을 미친다는 여러 선행연구들과 부분적으 로 일치한다(Kang, 2011; Kim, 2005). 또한, 실험집단 과 통제집단 간의 비교에서 자기효능감과 운동의 장점, 단점은 차이를 보였지만, 통계적으로 유의한 차이를 보이 지 않았다.

한편, 동기의 측면에서 실험집단의 확인규제는 긍정적 인 향상을 보인 반면, 집단 간에는 유의한 차이를 확인하 지 못하였고, 내적규제, 무동기, 외적규제, 의무감규제와 같은 변인들은 집단 내, 집단 간에서 모두 유의한 차이를 보이지 않았다. 이와 같은 결과는 심리기술훈련을 적용한 결과, 고등학교 태권도 선수들의 동기와 스포츠 자기효능 감 향상의 유의성을 검증한 Yang(2014)의 연구결과와 차이를 보인다. 또한, 신체활동의 변화단계를 예측하기 위해 자결성이론을 적용한 선행연구(Kim et al., 2007) 에서는 행동규제의 하위변인인 내적규제, 확인규제, 의 무감규제, 외적규제, 무동기는 신체활동 단계와 유의한 관련이 있다고 보고하였다. 즉, 신체활동 단계가 높아질 수록 행동규제의 모든 하위변인들은 긍정적인 변화를 나 타낸다고 보고한 선행연구와 본연구의 결과와는 차이를 보였다. 
12 주간의 운동정보제공 처치전략을 제공한 결과, 실 험집단의 신체활동량과 운동의 장점과 단점, 자기효능 감, 확인규제와 같은 변인들이 통제집단과 비교할 때 긍 정적으로 변화했지만, 집단 간에는 통계적으로 유의한 차 이를 보이지 않았고, 내적규제, 의무감규제, 외적규제, 무동기는 시간의 흐름 및 집단 간의 비교에서도 차이를 확인할 수 없었다.

본 연구에서는 현재 소셜미디어를 활용한 심리전략 연 구가 매우 부족하다는 점을 고려하여 건강운동심리학 분 야에서 최근 수행되었던 신체활동 및 이와 관련된 심리요 인의 증진과 관련된 선행연구들을 고찰하여 논의하였다.

Kang \& Lee(2017)의 SPARK(Sport, Play and Active, Recreation for kids) 신체활동 증진 프로그램을 여고생 체력수업에 적용한 연구에서는 하루 일과의 대부 분을 학교에서 보내고, 학업에 쫓겨 충분한 신체활동에 참여하지 못하는 고등학생들의 사회적, 환경적 요인을 고 려한 후속연구가 필요하다고 제언하였다(Kang \& Lee, 2017). 국외의 사례를 살펴보자면, 'e-health 중재전략' 이 신체활동 촉진에 미치는 영향을 규명함으로써(Rick Yiu et al., 2020) 본 연구의 결과를 부분적으로 입증하 고 있다. 이에따라, 신체활동 참여와 증진에 주요한 영향 을 미치는 심리요인들의 변화를 위해 소셜미디어를 활용 한 중재전략의 필요성을 추론해 볼 수 있을 것이다.

결과적으로, 신체활동과 관련된 긍정적인 심리적 특성 들이 비활동 대학생의 인지적 변화과정 전략의 사용을 증 가시킨 것으로 판단된다. 하지만, 실험, 통제집단의 심리 변인의 변화 차이에는 통계적으로 유의한 차이가 발견되 지 않았다. 실험집단과 통제집단 모두 학기 중의 대학생 들이었기 때문에 여러 전공강의 또는 다양한 교양강의를 수강하고 있었다는 점이 이와 같은 결과에 부분적으로 영 향을 미쳤다고 사료된다. 설명하자면, 본 연구의 대상은 신체활동에 참여할 의도가 없고, 현재 신체활동을 하지 않고 있는 비활동 대학생이기 때문에 축구, 농구, 볼링 등 의 기술적인 능력 습득을 목표로 개설되는 교양체육 강의 에 참여하는 학생들은 연구대상자에서 제외하였으나, 교 양체육 강의가 아니더라도 다양한 강의에서 신체활동, 운 동과 건강에 관련된 정보를 습득할 수 있는 가능성이 있 다. 또한, 본 연구는 SNS를 통해 운동정보를 제공하기 때 문에 실험기간 동안 카카오톡 단체 채팅방을 이용한 공지
를 제외하고는 연구자와 연구 참여자 간의 직접적인 접촉 이 없었다. 이에, 연구 참여자의 예측할 수 없는 생활 사 건과 환경들을 완벽하게 통제하기에 한계가 있었고, 통제 집단 역시 설문지를 통한 사전검사 이후, 중간, 사후 측정 시 실험집단과 같은 설문에 답변을 함으로써 학습효과로 인한 변화가 발생할 수 있고, 생활속에서 자연스럽게 SNS를 사용함으로써 운동과 관련된 정보를 포함한 다양 한 정보에 노출될 가능성을 배제하지 못하였기 때문이라 고 사료된다.

현재까지 신체활동의 혜택에 따른 필요성이 검증된 많 은 연구들이 개인의 신체활동과 이와 관련된 심리 변인들 을 긍정적으로 향상시키는데 있어 유의하게 작용한다는 결과를 보고하고 있지만, 여전히 노인을 제외한 20대의 적절한 신체활동 실천율이 가장 낮고 중강도 신체활동 실 천율 또한 가장 낮은 실정이다(Koh et al., 2007). 따라 서, 대학생들의 신체활동 참여율을 높이고, 관련 심리요 인을 긍정적으로 향상시키기 위해 현장에서 직접적으로 처치전략을 적용함에 따르는 시간 부족, 공간의 제약 등 으로 신체활동을 지속적으로 실시하는데 한계가 있었던 부분들을 되짚어보며 'SNS 이용률이 가장 높은 대학생' 의 특성을 중점에 두고 신체활동 참여와 인식의 변화를 연구하고 분석하였다. 2013 Survey on the internet usage(Korea Internet \& Security Agency, 2013)에서 는 인터넷 이용자가 모바일 중심으로 변화하고 있다고 보 고하면서, SNS 이용자 10명 중 9명 (93.8\%)이 '스마트 폰' 을 통해 SNS를 이용하고 있고, 20대의 SNS 이용률 이 $87.5 \%$ 로 다른 연령대에 비해 확연하게 높게 나타났다 고 하였다. 이러한 인터넷 이용 환경의 변화로 인해 본 연 구와 같이 SNS를 이용한 다양한 교육에 관한 연구가 진 행되고 있다. Kyung Hee University Research Institute of Educational Development(2011)에서는 대학수업에서 다양한 SNS를 교육에 적용하는 연구가 진 행되고 있고, SNS 활용이 교수자와 학습자 사이의 상호 작용과 학습자의 자발적 학습에 좋은 환경을 제공한다는 긍정적인 연구 결과들을 확인했다고 보고하였다. 이처럼 여러 방면에서 SNS를 적용한 연구가 이루어지고 있지 만, 운동심리학의 영역에서는 비교적 다루어지지 않았던 'Social network'을 기반으로한 심리전략을 현장에 적용 하였다는 것이 본 연구의 강점이라고 판단된다. 
본 연구는 $\mathrm{SNS}$ 를 활용하여 신체활동에 관련된 정보를 제공함으로써 비활동 대학생의 신체활동과 심리 변인의 긍정적 변화를 유도하였다. 이는 직접적인 처치를 적용하 는 현장연구에 비해 상대적으로 적은 비용과 시간, 공간 의 제약에 자유로울 것이다. 또 다른 장점으로는 비활동 대학생의 신체활동과 이와 관련된 심리적 결정요인을 12 주간의 종단적인 관점에서 연구하였다는 것이다. 본 연구 를 통해 SNS와 같은 최첨단 미디어를 활용한 신체활동에 관한 새로운 접근방식이 새로운 사회, 문화적 변화에 민 감한 대학생에게 규칙적인 신체활동 참여에 흥미를 유발 할 수 있을 것이라 생각된다. 이에 따라, 대학생들의 신체 활동량 감소와 부정적인 심리변인들을 긍정적으로 변화 시키고, 올바른 운동습관 형성과 규칙적인 신체활동을 통 한 건강 증진에 관한 문제를 효율적으로 해결할 수 있는 대책이 마련되고 실행될 것을 기대한다.

\section{결론 및 제언}

본 연구에서는 SNS를 활용한 심리전략이 비활동 대학 생의 신체활동과 심리 변인에 미치는 영향을 검증하였고, 다음과 같은 결론을 얻었다. 첫째, 12 주 동안의 $\mathrm{SNS}$ 를 활용한 운동정보제공은 실험그룹에 속한 비활동 대학생 의 신체활동 변화단계를 향상시키는데 긍정적으로 작용 하였고, 시간의 흐름에 따라 비활동 대학생의 신체활동 및 의사결정균형, 자기효능감, 확인규제와 같은 심리 변 인이 유의하게 향상되었지만, 집단 간의 차이는 나타나지 않았다. 또한, 비활동 대학생의 무동기, 외적규제, 의무 감규제, 내적규제의 항목에서는 긍정적인 변화를 확인하 지 못하였고, 집단 간의 차이도 발견할 수 없었다.

위와 같은 결론을 바탕으로 제언하자면, 후속 연구에 서는 연구대상을 다양하게 확대하고, 연구 참여자의 여러 상황과 환경을 고려하여 체계적이고 일관성 있는 실험 환 경을 조성해야 할 것으로 생각된다. 또한, 양적인 분석 뿐 만아니라 신체활동과 관련된 심리적인 측면에 관한 질적 인 분석도 적용해야 할 것이다. 마지막으로, 본 연구에서 사용된 카카오톡과 네이버포스트 뿐만아니라 연구대상 과 시대적 흐름을 고려하여 다양한 프로그램들을 사용한 다면 신체활동 증진에 긍정적인 영향을 미치는 다양한 심
리적 특성의 중요성을 고려한 여러 가지 운동정보 또는 프로그램을 연구하는데 사용될 수 있을 것으로 생각된다.

\section{참고문헌}

Ashworth, P. (1997). Breakthrough or bandwagon? Are interventions tailored to Stage of Change more effective than non-staged interventions? Health Education Journal, 56(2), 166-174.

Abrantes, Ana. M., Blevins, Claire., Lindsay, Clifford., Battle, Cynthia. L., Buman, Matthew. P., Agu, Emmmanuel. \& Stein, Michael. (2019). Formative work in the development of a physical activity smartphone app targeted for patients with alcohol use disorders. Psychology of Sport \& Exercise, 41.

Bandura, A. (1997). Self-efficacy: The exercise of control. New York: Freeman \& Co.

Banting, L. K., Dimmock, J. A. \& Lay, B. S. (2009). The role of implicit and explicit components of exerciser self-schema in the prediction of exercise behaviour. Psychology of Sport and Exercise, 10, 80-86.

Blissmer, B. \& McAuley, E. (2002). Testing the requirements on stage of physical activity among adults: The comparative effectiveness of stage-matched, mismatched, standard care, and control interventions. Annals of Behavioral Medicine, 24, 181-189.

Brown, W. J., Ford, J. H., Burton, N. W. \& Marshall, A. J. (2005). Prospective study of physical activity and depressive symptoms in middle-aged women. Am. J. Med, 29, 265-272.

Burbaker, B. (1983). Health Promotion: A linguistic analysis. Advanced in Nursing Science, 5(3), 1-14.

Best, Krista., Routhier, Francois., Sweet, Shane. N., Arbour-Nicitopoulos, Kelly. P., Borisoff, Jaimie. F., Noreau, Luc. \& Martin Ginis, Kathleen. A. (2016). Development of a smartphone-delivered peer physical activity counselling program for manual wheelchair users: A mixed-methods approach. Archives of Physical Medicine \& Rehabilitation. 97(1).

Cardinal, B. J. \& Kosma, M. (2004). Self-efficay and the stages and processes of change associated with adopting and maintaining muscular fitness-promoting behaviors. Research Quarterly for Exercise and Sport, 75(2), 186-196. 
Cho, Y. K. (2013). The effects of participation according to the sports event SNS(Social network service) usage on the reusing intention and brand royalty. M.S. Thesis, Ewha Womans University.

Choi, Y. H. \& Chae, M. J. (2020). Development and effects of smartphone app-based walking exercise program for texi drivers: Based on Bandura's self-efficacy theory. Journal of Korean Academy of Nursing. 50(2), 242-254.

Cumming, J. (2008). Investigation the relationship between exercise imagery, leisure-time exercise behavior, and self-efficacy. Journal of Applied Sport Psychology, 20, 184-198.

David, N. C., Deborah, F. T., Amy, V. R., Jane, D. B., Robert, F. D. \& Alice, S. A. (2012). A social media-based physical activity intervention. Prevent Medicine Reports, 43(5), 527-532.

Deighton-Smith, N. \& Bell, B. T. (2018). Objectifying fitness: A content and thematic analysis of \#fitspiration images on social media. Psychology of Popular Media Culture, 7(4), 467-483.

Fallon, E. A., Hausenblas, H. A. \& Nigg, C. R. (2005). The transtheoretical model and exercise adherence: examining construct associations in later stage of change. Psychology of Sport and Exercise, 7, 1-13.

Godin, G. \& Shephard, R. J. (1985). A simple method to assess exercise behavior in the community. Can J Appl Sport Sci, 10(3).

Griffin-Blake, S. \& DeJoy, D. M. (2006). Evaluation of social-cognitive versus stage-matched, self-help physical activity interventions at the workplace. American Journal of Health Promotion, 20, 200-209.

Hongu, Nobuco., Going, Scott. B., Orr, Barron, J., Merchant, Nirav. C., Hingle, Melanie. D., Roe, Denise. J., Greenblatt, Yael. V. \& Houtkooper, Lina. B. (2014). Mobile technologies for promoting health and physical activity. ACSM's Health \& Fitness Journal, 18(4).

Jackson, E. M. \& Howton, A. (2008). Differences according to body mass index. Journal of American College Health, 57(2), 159-164.

Jingwen, Z., Devon, B., Sijia, Y., Joshua, B., Natali, H. \& Damon, C. (2016). Support or competition? How online social networks increase physical activity: A randomized controlled trial. Prevent Medicine Reports, 4. 453-458.

Kang, J. H. (2011). Effect of sleep hours and physical activity on psychological factors in children. The Korean Journal of
Elementary Physical Education, 17(1). 63-72.

Kang, H. K. \& Lee, G. I. (2017). Design and implementation of physical education class for female high school students using the promotion strategies of physical activity. The Korean Journal of Physical Education, 56(1), 287-304.

Keum, C. K. (2016). Factors affecting the continuance intention to use of social network service user. Business Administration. $\mathrm{Ph} . \mathrm{D}$. Dissertation, Namseoul University.

Ki, E. J. \& So, H. S. (2020). Development and effects of smartphone app-based exercise program for hemodialysis parients. Journal of Korean Academy of Nursing, 50(1), 52-65.

Kim, C. J., Hwang, A. R. \& Yoo, J. S. (2004). The impact of a stage-matched intervention to promote exercise behavior in participants with type 2 diabetes. International Journal of Nursing Studies, 41, 833-841.

Kim, H. K. (2012). The effects of smartphone application to increase physical activity among university students. M.S. Thesis, Seoul National University.

Kim, J. H. (2018). Effects of physical activity and psychological modification-based intervention strategies on physical fitness and psychological variables in middle school girls. M.S. Thesis, Seoul National University of Science and Technology.

Kim, J. M., Koh, K. W., Kim, Y. J. \& Shin, Y. H. (2011). Status of and challenges for physical activity in Korean university students. Korean Journal of Health Education and Promotion, 28(5), 51-60.

Kim, S. W. (2005). Influence of exercise on EEG hemispheric asymmetry and emotion. Ph.D. Dissertation, Kyungpook National University.

Kim, Y. H. (2002). Adolescents' stages of change, decision balance, self-efficacy in exercise: Application of Transtheoretical model. Korean Society of Sport Psychology, 13(3), 1-19.

Kim, Y. H. (2004). Korean and American university students' exercise behavior: Application of psychological variables to predicting stages of change. Korean Society of Sport Psychology, 15(2), 29-43.

Kim, Y. H. (2006). Understanding social cognitive variables to influencing changes in physical activity behavior. Journal of Sport and Leisure Studies, 27, 165-176.

Kim, Y. H. (2007). Effects of lifestyle-based stage-matched intervention on adults' physical activity and its related psychological variables. Korean Journal of Sport Science, $18(2), 62-73$. 
Kim, Y. H., Cardinal, B. J. \& Lee, J. Y. (2006). Understanding exercise behavior among Korean adults: a test of the transtheoretical model. International Journal of Behavioral Medicine, 13, 295-303.

Kim, Y. H., Kim, H. S. \& Kang, S. J. (2013). Effects of obesity management program on changes in bodymass, physical activity and its related psychological variables in obesity adolescents. Korean Society of Sport Psychology, 24(1), 193-208.

Kim, Y. H., Yang, J. K. \& Lee, J. H. (2007). Application of self-determination theory to predicting stages of change for physical activity behavior. Korean Journal of Sport Science, 18(4), 208-217.

Korea Internet \& Security Agency (2013). Survey on the Internet Usage.

Kyung Hee University Research Institute of Educational Development (2011). "A Study on e-Learning Teaching Model using SNS and Smart Phone"

Lee, T. H. (2004). Psychological determinants of exercise behavior according to exercise stages of university students. M.S. Thesis, Seoul National University of Science and Technology.

Lee, S. Y. \& Jung, I. S. (2010). An exploratory study on social network service in the context of web 2.0 period. Management \& Information System Review, 29(4), 143-167.

Lengfelder, M. E. (2001). Sind uranhaltige Waffen schuld an den Leukamiefallen? MMW - MUNCHEN-, 143, 10-11.

Lippke, S., Ziegelmann, J. P. \& Schwarzer, R. (2005). Stage-specific adoption and maintenance of physical activity: testing a three-stage model. Psychology of Sport and Exercise, 6, 585-603.

Mullan, E., Markland, D. \& Ingledew, D. K. (1997). A graded conceptualization of self-determination in the regulation of exercise behavior: Development of a measure using confirmatory factor analytic procedure. Personality and Individual Differences, 23, 745-752.

Marcus, B. H. \& Forsyth, L. H. (2003). Physical activity intervention series: Motivating people to be physically active. Human Kinetics, Champaign, IL.

Marcus, B. H. \& Lewis, B. A. (2003). Physical activity and the stages of motivational readiness for change model. President's Council on Physical Fitness and Sports Research Digest. Series 4.

Marcus, B. H., Selby, B. C., Niaura, V.C. \& Rossi, J. S. (1992).
Self-efficacy and stage of exercise behaviors change. Res $Q$ Exer Sport, 63(1), 60-66.

Marcus, B. H., Simkin, L. R., Rossi, J. S. \& Pinto, B. M. (1996). Longitudinal shifts in employees' stages and processes of exercise behavior change. American Journal of Health Promotion, 10, 195-200.

Ministry of Health and Welfare (2011). Health examination statistics.

Ministry of Science and ICT (2019). Survey on the Internet Usage.

Park, J. H., Kim, B. S., Choi, H. L., Won, J. W. \& Chio, C. Y. (2001). Comparing students of college of physical education and general college: Relationship between physical activity and the amount of maximal oxygen uptake of the freshmen of a university. Korean Journal of Family Medicine, 22(11), 1637-1646.

Park, J. W. (2017). Difference on amount of physical activity by factors on physical activity participation of undergraduate. M.S. Thesis, Korea National University of Education.

Plotnikoff, R. C., Blanchard, C., Hotz, S. \& Rhodes, R. (2001). Validation of the decisional balance constructs for the transtheoretical model in the exercise domain. Measurement in Physical Education and Exercise Science, 5, 191-206.

Prochaska, J. O. \& Marcus, B. H. (1994). The transtheoretical model: Applications to exercise. In Dishman, R. K. (ed.). Advances in Exercise Adherence. Human Kinetics, Champaign, IL, pp. 161-180.

Rick Yiu Cho Kwan, Dauda Salihu, Paul Hong Lee, Mimi Tse, Daphne Sze Ki Cheung, Inthira Roopsawang \& Kup Sze Choi. (2020). The effect of e-health interventions promoting physical activity in older people. European Review of Aging and Physical activity, 17(7).

Sallis, J. E. \& Owen, N. (1999). Physical activity and behavioral medicine. Thousand Oaks, CA: Sage.

Seol, D. H. (1996). Study on actual conditions of college students' leisure activities. Student life study, 7, 27-50.

Statistics Korea (2019). Korean indicator of Education. \& Korean indicator of Physical activity.

United States Department of Health and Human Services (1996). Physical Activity and Health: A Report of the Surgeon General. US Department of Health and Human Services, Centers for Disease Control and Prevention, National Center for Chronic Disease Prevention and Health Promotion, Atlanta, GA. 
Wilson, P. M., Rodgers, W. M., Fraser, S. N. \& Murray, T. C. (2004). Relationships between exercise regulations and motivation consequences in university students. Research Quarterly for Exercise and Sport, 75, 81-91.
Yang, J. E. (2014). The effects of psychologial skills training on competitive anxiety, intrinsic motivation, sports self-confidence, performance strategy and perceived performance of high school Teakwondo players. M.S. Thesis, Dong Eui University.

\title{
$\mathrm{SNS}$ (사회관계망서비스)를 활용한 운동정보제공이 비활동 대학생의 신체활동과 심리 변인에 미치는 영향
}

\author{
안도진 ${ }^{1}$, 김영호 $^{2}$, 강수진 ${ }^{3}$ \\ ${ }^{1}$ 서울과학기술대학교, 석사 \\ ${ }^{2}$ 서울과학기술대학교, 교수 \\ ${ }^{3}$ 서울과학기술대학교, 강사
}

[목적〕 본 연구는 SNS를 통한 운동정보제공이 대학생의 신체, 심리 변인의 변화에 영향을 미치는지를 확 인하여 SNS를 활용한 운동정보제공의 유효성을 검증하는데 그 목적이 있다. 〔방법) 전체 연구대상은 자발적 인 의사에 의하여 연구에 참여한 신체활동을 하지 않고 있는 대학생 60 명으로 무선으로 할당하여 각각 실험집 단 30 명, 통제집단 30 명이다. 이들은 각각 사전검사 후 실험집단에게는 운동정보를 제공하였고, 통제집단에 게는 운동정보를 제공하지 않고 6 주, 12 주차에 반복 측정하였다. 수집된 자료는 빈도분석, 카이제곱검정과 반복측정 분산분석을 통하여 분석하였다. 모든 통계 분석은 SPSS 23.0을 사용하였다. 〔결과) SNS를 활용 한 운동정보제공은 비활동 대학생의 신체활동량과 신체활동단계변화에 긍정적인 영향을 미치는 것으로 나타났 다. 그리고 비활동 대학생의 의사결정균형, 자기효능감, 동기는 시간의 흐름에 따라 제공되는 운동정보이 양이 늘어나면서 긍정적인 영향을 보였지만, 집단 간 차이에는 유의한 영향을 미치지 않았다. 〔결론) SNS와 같은 다양한 미디어의 활용을 통한 심리전략의 제공은 비활동 대학생의 신체활동 참여율을 높이고, 관련 심리요인 의 향상에 긍정적인 영향을 미칠 것이다.

주요어: 비활동 대학생, 신체활동, 심리전략, 사회관계망서비스, 단계변화모형 